\title{
Utility Interface Requirements for a Solar Power System
}

September 1978

\section{MASTER}

U.S. Department of Energy

Office of Energy Research

Satellite Power System Project Office

\section{DOE/NASA}

SATELLITE POWER SYSTEM

Concept Development

and

Evaluation Program 


\section{DISCLAIMER}

This report was prepared as an account of work sponsored by an agency of the United States Government. Neither the United States Government nor any agency Thereof, nor any of their employees, makes any warranty, express or implied, or assumes any legal liability or responsibility for the accuracy, completeness, or usefulness of any information, apparatus, product, or process disclosed, or represents that its use would not infringe privately owned rights. Reference herein to any specific commercial product, process, or service by trade name, trademark, manufacturer, or otherwise does not necessarily constitute or imply its endorsement, recommendation, or favoring by the United States Government or any agency thereof. The views and opinions of authors expressed herein do not necessarily state or reflect those of the United States Government or any agency thereof. 


\section{DISCLAIMER}

Portions of this document may be illegible in electronic image products. Images are produced from the best available original document. 


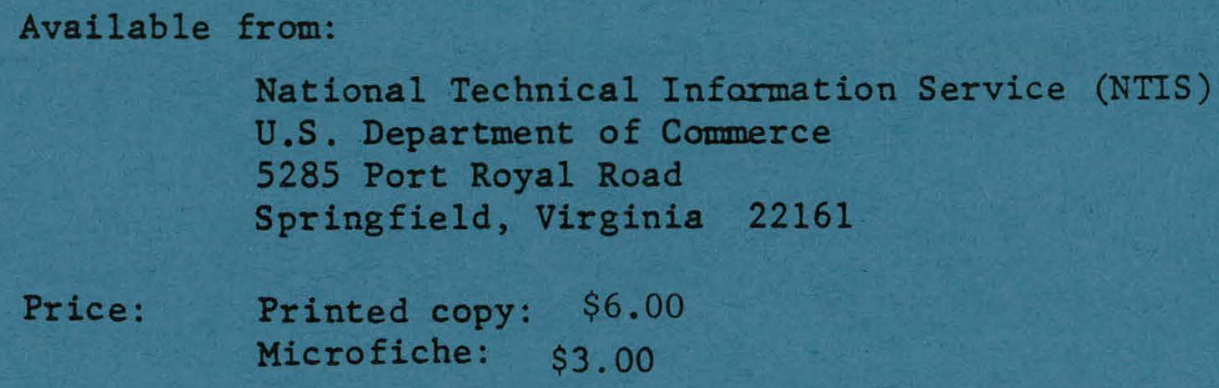


Distr. Category UC-11, 41, 60, 63, 63a, b, c, e $64,66 \mathrm{e}, 95 \mathrm{f}, 97 \mathrm{c}$

\section{Utility Interface Requirements for a Solar Power System}

September 1978

Prepared by:

P. J. Donalek and J. L. Whysong

Harza Engineering Company

Chicago, Illinois 60606

for the

Argonne National Laboratory

Argonne, Illinois 60439

Prepared for:

U.S. Department of Energy

Office of Energy Research

Satellite Power System Project Office

Washington, D.C. 20585

Under Contract No. 31-109-38-4142

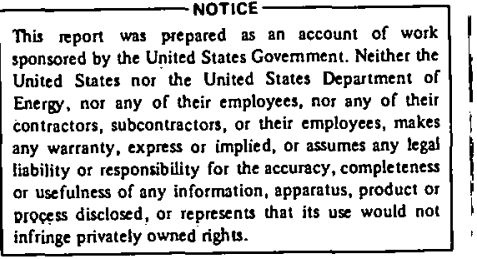

\section{DOE/NASA}

\section{SATELLITE POWER SYSTEM}

Concept Development

and

Evaluation Program 
THIS PAGE

\section{WAS INTENTIONALLY LEFT BLANK}




\section{Table of Contents}

\section{Page}

Introduction

Summary

General

Load Estimates

Transmission System

Rectenna Site Location

Rectenna Substation Design

Operational Problems

System Capacity Mix

Rectenna Maintenance

Environmental Considerations

References

Tables

Diagrams 


\section{Index of Tables and Figures}

$\begin{array}{lll}\text { Tables } & \text { I } & \text { List of Problem Areas } \\ & \text { II } & \text { Metropolitan Area Loads and Transmission Mileage } \\ \text { Diagrams } & 1 & \text { Rectenna Power Flow Schematic } \\ 2 & \text { Metropolitan Areas and Peak Loads } \\ 3 & \text { Metropolitan Area Clusters and Loads } \\ 4 & \text { Ut1lity l'ransmission Systems } \\ 5 & \text { Transmission Line Loading Curve } \\ 6 & \text { Rectenna Land Requirement } \\ 7 & \text { Possible Rectenna Sites } \\ 8 & \text { Rectenna Sites and Metropolitan Areas } \\ 9 & \text { Propoocd Rectenna Deldils } \\ 10 & \text { Rectenna Dimensions } \\ 11 & 69 \mathrm{kV} \text { Power Collection Farilities } \\ 12 & 500 \mathrm{kV} \text { Substation Facilities } \\ 13 & 345 \mathrm{kV} \text { Substation Facilities }\end{array}$


The authors wish to acknowledge the following persons for the time taken to review the draft of this report and prepare written comments on it:

Mr. D. W. Gilman

San Diego Gas and Electric Company

101 Ash Street

San Diego, California 92101

Dr. Kirit S. Shah (for H. N. McCoy)

Manager of System Planning

Union Electric Company

1901 Gratiot Street

St. Louis, Missouri 63103 


\section{Solar Power System - Utility Interface}

\section{Introduction}

The following is a final report on work done by Harza Engineering, under a contract $1 /$ with the EES Division of Argonne National Laboratory. The general scope of the study is to make an overview analysis of problems associated with the interface between a Satellite Power system (SPS) and a group of electric utility systems.

For this study it was specified that the southern tier of the United States (South of the 36th parallel) should be examined to see what problems might develop with the installation of a Satellite Power system in the year 2000 . $\underline{\text { Summary }}$

One or more $5 \mathrm{GW}$ SPS units could be installed in the utility systems of the southern states in the year 2000. The $345 \mathrm{kV}$ and $500 \mathrm{kV}$ transmission systems which will probably exist at that time could be readily extended to accomodate the sps units.

The operation of the SPS units will present the utilities with new and difficult problems in system stability and frequency control. The problems will arise because a somewhat variable 5 SW nitput will be produced by a generator having no mechanical inertia.

The unavoidable time lag in controlling the position of the energy beam at the receiving station may have a very critical effect on the stability of the utility systems. 1/ Contract number 31-109-38-4142 as amended 
At least 10 years advance notice of the installation of an SPS unit, specifying the proposed location, must be given the adjoining utility companies. This advance notice is necessary so that the utilities can incorporate the sPs unit into their capacity plans.

The maintenance problems associated with the energy receiving device, a continuous structure covering more than 4.0 square miles, must be given careful consideration. Repair of lightning damage while maintaining SPS operation may be the most critical requirement.

Acquisition and preparation of the 90 square miles of land required for the receiving antenna (rectenna) will create many new and difficult environmental problems.

A list of major problem areas is given by Table I at the end of this report. Many of these problems cannot be resolved until the basic design of the rectenna has been establisher. 


\section{General}

In a conventional hydroelectric plant mechanical energy stored in a large lake or reservoir is delivered by a stream of water to the electric generating station. In a conventional steam generating station, chemical energy in the form of fuel is delivered by rail, barge or pipeline to a plant occupying possibly one square mile of land area. The energy stored in the fuel is converted to electrical energy in blocks of capacity ranging in size from a few MW to as large as $1200 \mathrm{MW}$. In contrast, solar energy will be delivered to an SPS plant by means of an electromagnetic beam operating at a frequency of $2.54 \mathrm{GHz}$. The SPS plant that converts electromagnetic energy for delivery to a utility system may require a land area of nearly 90 square miles. For economic reasons the smallest unit of capacity for a sps will be about 5GW.

A conventional hydro plant may create environmental problems with its reservoir and spillways. A steam. plant r.pates environmental problems associated with the mining, processing, and transportation of fuel; air pollution from burning fuel; water problems from flue gas scrubbing and cooling water requirements; and other land utilization problems arising from ash and sludge disposal: A SPS avoids some of the pollution problems but adds others associated with the requirement for large land areas, very great usage of metalic natural resources and the possibility of producing electromagnetic pollution. 
The economics of the SPS conversion process is directly concerned with the collecting of small increments of microwave energy and converting them into larger increments of low frequency $(60 \mathrm{~Hz})$ energy as illustrated by Figure 1 . Although the utility system has no direct interest in the detailed design of the energy receiving device and conversion equipment (rectenna) some features of that equipment may affect the utility interface. It is the purpose of this study to make a general examination of the utility problems associated with this interface. .

The procedure used for the study was as follows:

1) Existing reports were reviewed to establish starting conditions for the study, and to determine areas where additional information would be necessary. Primary references are listed at the end of this report.

2) The major load centers in the southern tier of states were defined and estimates were madc of the electric demand in these areas for the year 2000.

3) The relation between these load centers and the electrical transmission system was determined.

4) A number of possible SPS sites reasonably close to the metropolitan areas and planned transmission were selected.

5) The more favorable of these sites were examined to determine what problems might arise if a site were used for the receiving terminal of SPS in the year 2000 . 
6) A list of general problem areas requiring further examination is included as Table $I$. These problem areas are directly related to, but may not necessarily be within the scope of this study.

The following pages present detailed discussions of specific areas of interest, covered by the study. 


\section{Utility System Load Estimates}

In order to establish the utility system base data for the year 2000 two sources of data were used (1) the United States Statistical Abstract for 1977 and (2) the "Appendix A" Reports for 1978 published by, (SERC) South Eastern

- Reliability Council, (ERCOT) Electric Reliability Council of Texas, (SPP) Southwestern Power Pool and (WSCC) Western Systems Coordinating Council. The procedure for uṭilizing these data was as follows.

(1) The population by states and metropolitan areas for 1975 was obtained from the Statistical Abstract. The metropolitan areas for the southern states are shown by Figure 2 .

(2) Electric energy usage for 1975 (also from the Statistical Abstract) was allocated between metropolitan and other areas'in proportion to total population, except that industrial usaqe was allocated only to the metropolitan areas.

(3) The energy data were reassembled, by states and metropolitan areas, to conform to the boundaries of the four southern reliability councils.

(4) Information from the Appendix A reports including electric energy and demand data for the years 1977 through 1997 were used. Load factor data for 1977. and 78 were extrapolated back to 1975 to provide state and metro area 'demands for that year. Load growth data for 1995 to 1997 
were used to extend the load estimates to the year 2000 . The demand estimates for the metro areas were then extended to the year 2000, as shown by Table II and Figure 2.

(5) Estimates of load growth for the two year period immediately after 2000 were also made. These estimates provided a guide as to where later capacity additions might be required.

General siting Criteria

A general planning criteria used by some utilities requires that a system must be so designed and built that a single outage such as a generating unit, generating station, substation, transmission line or right of way will involve no more than 10 or $15 \%$ of the total system capacity.

Applying that criteria to a $5 \mathrm{GW}$ SPS unit indicates that such a unit should be connected into a utility system that has no less than $33 \mathrm{GW}$ of capacity or $27 \mathrm{GW}$ of load (assuming a reserve margin of $20 \%$ ).

Using these numbers as a rough guide, the metro areas. were grouped into oontiguous clusters of four to six areas which had combined demands in excess of $30 \mathrm{GW}$, Figure 3 . It was assumed that groups of this size, together with their associated non metro load could absorb the output of one SPS without requiring extensive revision of the existing transmission system. 


\section{Transmission System}

The transmission voltage suitable for the early sps installations can be selected quite readily based on only two criteria. (I) What are the existing and planned voltage levels in the area? (2) Do these voltage levels provide adequate transmission capacity for a particular sPs site?

Existing transmission line locations and voltages were obtained from a current series of Federal Power Commission maps. Transmission line additions planned through the year 1987 are 1dent1fled in the Appendix $\bar{A}$ Reports. Using this information the transmission pattern for the southern tier of states was determined. This pattern is shown schematically by Figure 4. All of the southeastern states are served by a $500-k V$ network which overlays a $230-k V$ system. East Texas and Oklahoma have an established $345-\mathrm{kV}$ network which overlays a 138-kV system. New Mexico, Arizona, Colorado and Utah will have established $345 \mathrm{kV}$ networks by 1987 although the system will be rather thin because of the light load densities in these states. Southern California will have both 345 and buU $\mathrm{kV}$ as well as high voltage direct current (HVDC) lines and the mixture of voltages will overlap into Arizona. No attempt was made to develop a detailed transmission pattern to the year 2000 on a line by line basis because that appeared unnecessary once the general pattern had been established. The SERC report stated that when the $500 \mathrm{kV}$ system became inadequate for the southeastern states they 
probably would consider a higher voltage near $1100 \mathrm{kV}$ for the next voltage step. Although not stated in the other reports it appears that $765 \mathrm{kV}$ would be considered as the next step up for the $345 \mathrm{kV}$ systems. Both of these patterns of voltage steps have already been established in other areas and are generally accepted by the utility industry.

Typical line loadings for these various voltage levels were determined from the line loading chart, Figure 5. The surge impedance load (SIL) of a line is defined as the load at which the $I^{2} X$ losses $^{*}$ of a line are equal to the charging VA. The permissible line loading is determined by using the multiplier from the chart applied to the SIL corresponding to the selected voltage level. When line loading is determined in this manner the same loading curve applied to all voltage levels. For short lines th'e loading is limited by conductor ampere capability and for long lines by stability limitations. The overall curve is based on a $5 \%$ voltage drop.

Assuming an average distance of about $100 \mathrm{miles}$ from an SPS rectenna to a metropolitan load center, Figure 5 shows that a $138 \mathrm{kV}$ line can carry only $105 \mathrm{MW}$ and a $230 \mathrm{KV}$ line 270 MW. Neither of these voltages provides sufficient capacity to be considered the basic transmission voltage for a $5 \mathrm{GW}$ source because too many circuits would be required. For the same 100 mile distance a $345 \mathrm{kV}$ circuit could carry $800 \mathrm{MW}$ and a double circuit tower line 1600 MW. A single circuit $50.0 \mathrm{kV}$ line can carry $1860 \mathrm{MW}$. Either. of these

reactive loss due to reactance of the line. 
voltages, using four circuits at $500 \mathrm{kV}$ or four double circuit tower lines at $345 \mathrm{kV}$, provides adequate transmission for a $5 \mathrm{GW}$ source, even with one tower line out of service. Higher transmission voltages of $765 \mathrm{kV}$ or $1100 \mathrm{kV} \mathrm{AC}$ or HVDC will not be necessary in the early stages of SPS development so long as rectennas can be located within about 200 miles of large load centers. 
Rectenna Site Location

A rectenna site for the southern states, south of the 36th parallel, will be roughly 8 miles wide in the East-West direction and 12 miles long in the North-South direction, see Figure 6 . The area covered by the actual antenna will be only 6.2 by 8.7 miles and oval in shape. The total land area required may be reduced somewhat from 96 square miles. to perhaps 80 square miles by eliminating part of the rectangular corner areas. Portions of the corner areas, however, may be used for electrical substation and maintenance facilities.

For this study, rectenna sites were selected using available highway maps together with other information on the geographical characteristics of the areas being consideration. The following general rules were used in making site selections.

(1) No towns or villages within the site rectangle (8 x 12 miles). There will be difficulty enough relocating individual families without multiplying the problem by creating the organized opposition to relocating even the smallest village.

(2) No federal or major State highways through the site. In some cases secondary highways would have to be moved, and local roads eliminated. Elimination of local roads should less difficult after the local population has been relocated. 
(3) The site area must be relatively flat thus eliminating all known mountainous and hilly areas. The amount of irregularity that can be tolerated will depend on the rectenna design. Much of the grading costs should be considered as part of a specific design cost rather than being lumped into the general site preparation costs.

(4) No large water areas within the site. Large water areas include lakes, ponds, rivers and creeks. Water areas of almost any size will make foundation and construction work more expensive. Large water areas would also require floating maintenance facilities in addition to the usual land based equipment. Any stream crossing the rows of rectenna panels might require multiple bridges to provide access for maintenance vehicles. Some small artificial streams may be necessary however to control drainage.

(5) No coastal sites were considered because of possible salt spray difficulties and increased possibility of hurricane damage. Such sites also restrict access for transmission lines. For purely economic reasons high capacity transmission lines tend to go through, rather than along the side of the areas they serve, thus lines associated with costal areas are usually some distance inland. Transmission for a costal SPS site might tend to be concentrated into a corridor extending inland from the site and thus be more susceptible to total outages. 
It was found that these few rules were so restrictive that relatively few ( 6 to 8 ) possible sites were found in any state, see Figure 7. Actual on-site inspections would no doubt eliminate some of these possibilities but might discover others.

Site selection problems are not all of the physical type. A few of the other problems which may have to be considered are:

(1) The site area of 96 square miles is larger than many townships. The effect on township government, fire protection districts, school districts, road commissions or other taxing bodies must be considered.

(2) Even in lightly settled areas it will be necessary to relocate'a large number of families with their associated schools, churches and cemeteries.

Figure 8 shows the relation of the more favorable rectenna sites to metropolitan areas. Many more sites axe no doubt available in west Texas, New Mexico, and Arizona but the only.metropolitan areas are El Paso, Albuquerque, Phoenix, and Tucson. None of these are large enough to absorb a $5 \mathrm{GW}$, electrical supply. Much of the power produced by an SPS located near these areas would have to be exported to other areas some distance away. The additional transmission required might make the location uneconomic, at least in the early stages of the sps project. 
The lines shown in Figure 8 indicate proposed transmission connections without regard to geographic restrictions. The transmission distances for the more favorable sites are shown in Table II. Airline distances were scaled and then multiplied by 1.2 to provide an allowance for line routing details.

In general only four $500 \mathrm{kV}$ lines will be required for each 5 GW SPS under favorable power flow conditions. However, most of the metro area groupings can accommodate five or six lines if necessary. For most of the groupings possible alternative sites have also been shown. Each grouping also provides a number of different transmission possibilities. Consider the Georgia-Alabama group on the first page of Table II. The loads of the Atlanta and Birminghan areas will total nearly $30 \mathrm{GW}$. Allowing for subtransmission ties to surrounding rural areas, these two cities could absorb the output of one SPS. Adequate transmission could be provided by building two lines to each of those areas and omitting the lines to Montgomery, Macon and Columbus. The total transmission mileage required by site Al would be 404 miles. This could be reduced to 336 miles by using site A2 which is on a more direct line between the two areas.

In the Carolinas group, six transmission lines are indicated but probably no more than five are required. The load is so evenly distributed between the areas, however, that load flow studies would be necessary to determine the most desirable arrangement. 
Jacksonville, in the Florida group, accounts for only $10 \%$ of the load but $30 \%$ of the transmission mileage if site Cl is used. If Jacksonville is omitted, site C2 is nearer the center of load and transmission mileage is reduced by 25\%. Neither of the Florida sites is particularly attractive, however, because of the high probability of hurricane damage and the fact that possible interconnections with other systems are so limited.

In the Tennessee group it would appear desirable to omit Memphis, add the Knoxville-Bristol-Kingston areas, and chose a site closer to the center of load. However, such a site would be in hill country and this situation raises the question of just how much irregularity in ground elevation can be accepted. There will no doubt be an economic balance point between the cost of flat land and the cost of grading uneven or hilly land.

New Orleans, in the Louisiana group, provides nearly $40 \%$ of the group load and transmission requirements could be' reduccd if a near hy site could be found. However, such a site would be more susceptable to hurricane damage and land in this area not presently being farmed might possibly present rather unstable foundation conditions. Site E2 has the advantage that; if the line to Beaumont, Texas is omitted, only one transmission crossing of the Mississippi is required whereas Site El may require three river crossings. 
Refering to the Texas and Oklahoma groupings, a minor complication here is that the $345 \mathrm{kV}$ system voltage requires the use of double circuit tower lines. Because of the concentration of load at Houston and Dallas-FortWorth, Site G, midway between them, appears quite desirable. However, using sites $\mathrm{F}$ and $\mathrm{H}$ in the groupings shown by Figure 8 makes it possible to serve additional loads in Texas and Oklahoma. As a location for an initial SPS installation, a site in the desert area about 100 miles NE of Los Angeles, Figure 8 location Jl, would probably be suitabie. The site could lie partly or entirely on government owned property. Because of California's interest in environmental matters that state might be more interested than some others in having the first SPS installation. A desert location on government land would probably require the least effort in relocating people and would also produce the least distrubance if the SPS system should malfunction in any way.

The location would be reasonably close to existing 500 kV transmission lines, Figure 4. These lines and associated substation facilities would help to provide direct connections to the Los Angeles load area which is expected to be in excess of $36 \mathrm{GW}$ by the year 2000, Figures 2 and 3 ,

The desert location will reduce, though not eliminate, the amount of rectenna damage that may be caused by lightning and it would also minimize the expense that might be required to control surface drainage problems. 
As an alternative location, or as a site for a second SPS, location Al in west central Georgia would be very good. The load to be served in that area may be somewhat greater than in the Los Angeles area and the site will be surrounded by a strongly integrated $500 \mathrm{kV}$ transmission system. Environmental and sociological problems associated with this site may be much more typical of future developments than the California site.

It appears that for the early sPs installations most of , the transmission lines would be between 100 and 150 miles long. The $345 \mathrm{kV}$ areas will generally require somewhat longer lines. Specific transmission plans will, of course, require detailed studies.

Examination of Figure 8 shows that possibly eight $5 \mathrm{GW}$ SPS units could be used to help supply the metropolitan areas of the'southern states in the year 2000. After two years of load growth perhaps five more units could be interspersed between these areas. To go beyond these limited installations it will be necessary to serve areas further north where there are greater concentrations of load. Conditions producing increased load will make sPS siting much more difficult probably resulting in longer transmission lines. In any event more detailed studies, beyond the scope of this study, will be necessary to determine feasible patterns of development beyond the year 2000 . 


\section{Energy Parks}

Several years ago there was considerable interest in the possibility of having "nuclear parks" where several nuclear power piants could be installed along with a fuel reprocessing plant and a single large lake for cooling water. The associated transmission problems would have been difficult and the possible economic advantages were not at all clear.

SPS parks have been mentioned as a possible solution to the problem of land area requirements. If there is one area of 90 square miles available, there may be another nearby. This possibility may exist in the western desert areas of the U.S. but such a location would be hundreds of miles from the nearest concentration of load. The cost of the transmission system required would make the economics of an SPS park that much more doubtílul. However, if SPS sites cannot be found near load centers then SPS parks may become necessary. 
Rectenna substation Design

The basic features of the rectenna substation and power collection system are directly influenced by the design of the DC to AC converters. Detailed economic studies will be necessary to determine the optimum arrangement of the converter substations and the power collection system.

For this overview study the converters assumed are those discussed briefly in a previous study $2 /$, specifically they provide $40 \mathrm{MW}$ output at $69 \mathrm{kV}, 3$ phase, $60 \mathrm{~Hz}$. At least 125 of these converters would be required for the 5GW rectenna output, see Figure 9. Considering the size of the rectenna many, if not most, of these converter substations will be located within the active area of the rectenna. Most of the power output will be obtained from the central area of the rectenna and it may be neither practical nor economic to transmit that power to the edge of the active area at a relatively low DC voltage of 1 or $2 \mathrm{kV}$.

Some of the uncertainty in the substation design results from lack of knowledge as to the electrical characteristics of the $40 \mathrm{MW}$ converter unit, for example:

(1) What will the voltage regulating characteristic be? Will Load Tap Changing (LTC) be provided and what range will be required?

(2) How much harmonic filtering will be required and where will it be located? These facilities may affect the transient response of the total unit.

1/ Boeing-GE System Definition Study. D180-24071-1 Part III 
(3) What will be the response, both static and dynamic, of the converter and the associated rectenna elements to changing conditions and faults on adjoining DC or AC facilities?

(4) What will be the effect of an extended loss of load caused by the need to replace or repair a major piece of equipment such as a converter, transformer, or 69-kV line.

As presently visualized the rectenna will consist of inclined panels extending in continuous rows in an east-west direction. Each row will occupy a north-south ground space of about 100 feet, see Figure 10. Individual panels in each row may be as much as 32 feet wide (east-west) and 82 feet long (north-south). It should be possible with a reasonable design to locate a $40 \mathrm{MW}$ converter in the space underneath a row of rectenna panels and still have space for easy maintenance access.

Transmission at $69-\mathrm{kV}$ AC should be adequate to deliver $40 \mathrm{MW}$ from the center to the edge of the rectenna area where it could be collected as illustrated by Figure 11. This arrangement reduces the number of $69-\mathrm{kV}$ circuit breakers required at the expense of some small increase in capacity outage liability. Transmission lines inside the fipld would be underground and run parallel with the panel rows in order to facilitate fault location and maintenance. This plan would eliminate the extensive $69-\mathrm{kV}$ and $230-\mathrm{kV}$ buses required by the proposed design in Figure 9. The relative merits of these features would have to be evaluated. 
Figure 12 illustrates schematically how the individual transformers could be connected into a 500-kV ring that would encircle the rectenna site. This arrangement avoids the necessity of extending a large number of $69 \mathrm{kV}$ lines into the confines of an electrical switch yard and permits. connecting $500 \mathrm{kV}$ lines at any convenient point.

The ring buss arrangement makes it possible to distribute the effect of any line or transformer outage over all of the remaining facilities. This plan would be particularly effective for line outages as the adjacent utility systems should be able to withstand the effects of a single transmission line outage with no difficulty. The ring arrangement may also be helpful in aleviating a possible control problem that will be discussed later.

A similar ring bus arrangement would apply for connection to $345-\mathrm{kV}$ utility systems except that double circuit tower lines would be required, see Figure 13. The ring bus would also be of double circuit construction and the 350 MVA$345 / 69 \mathrm{kV}$ transformers would be connected to alternate circuits. The additional number of equipment items required at $345-\mathrm{kV}$ demonstrates that $500-\mathrm{kV}$ facilities may be somewhat. better suited to the 5-GW SPS application. 


\section{Operational Problems}

The SPS will present a special set of operating problems for the utility system because of variations in output resulting from (1) the annual seasonal variation (2) the semi-annual eclipse periods (3) and cyclic variations resulting from beam positioning error. There will also be those unidentified problems to be expected with any new technology which will be reflected by the utility system operating in an uneconomic manner.

Seasonal Variattons

The eccentricity of the earth's orbit together with the changing tilt of its axis will cause the power output of the SPS to vary on an annual seasonal basis. The SPS is presently designed to produce a minimum output of $5 \mathrm{GW}$. The seasonal change will increase the output to a maximum of about $5.5 \mathrm{GW}$ or 10 percent. There may be some gain in economics or efficiency if this seasonal fluctuation can be eliminated or at least reduced in magnitude. It is doubtful that storage of such a long time variation would be economic with any of the presently available storage techniques.

The most reasonable procedure may be to design the total system to accept and use all or part of this seasonal variation. If a single SPS represents no more than $15 \%$ of the capacity of the connected utility system then the seasonal variation will be no more than $1.5 \%$ of the same system. The effect on the utility system would be no different than it 
would be with conventional steam units which have reduced capacity in the summertime because of warm cooling water. Eclipse Periods

Twice each year there will be short periods when the satellite part of the SPS will be in the earth's shadow and as a result the power output will be reduced to zero. The eclipse periods occur around mignight during March and September of each year covering a span of 42 days at each time. The duration of each eclipse increase from a few minutes to a maximum of 72 minutes on the 21 st day and then declines to zero after 42 days.

Normal utility practice is to carry a spinning reserve of 2 to $3 \%$ of the peak load during heavy load periods. During light load periods the spinning reserve requirement can usually be satisfied from large base load units which cannot make overnight load reductions that are much greater then 50 percent of their ratings. Thus there appears to be an adequate amount spinning reserve available to cover ecllpse requirements. However, the problem will be to secure a sufficiently rapid response from these units to follow the load swing during the shorter eclipse periods. Some of the response may have to come from peaking units and some will no doubt have to be in the form of a frequency deviation. An important consideration may be that a major difference between conventional generation and the SPS is that the SPS provides power without adding inertia to the system. 
Special attention to problems of frequency stability and control may be required.

Beam Energy Variations

In addition to the large seasonal and eclipse variations in power output which will be known in advance and can be planned for there will be some smaller variations of interest. One small but important variation of special concern is that associated with controlling the position of the energy beam on the rectenna field. While the solar cell portion of the satellite maintains its orientation pointing toward the sun, the transmitting antenna must be aimed precisely at the rectenna. This aiming problem requires that the position of the beam on the rectenna be continuously adjusted. The beam adjustment is made at the transmitting antenna based on error signals produced at the rectenna. The time required for the control signals to go from transmitter to receiver and back to the transmitter is about 0.3 seconds. As a result the beam may tend to oscillate about the aiming point a frequency of about $3 \mathrm{~Hz}$. The beam position error may cause the rectenna output to fiuctuate by some small amount at this $3 \mathrm{~Hz}$ frequency.

Tnterconnected power eystoma have natural resunant frequencies which sometimes demonstrate their existance as small oscillations of system. voltages and currents that continue long after the originating disturbance has disappeared. The oscillations in the AC-DC Transmission loop on the west coast [8] are a good example of this phenomenon. 
Depending on the natural resonant frequencies that might exist in the surrounding utility system, oscillations in SPS output produced by the beam control system, might excite these natural frequencies and produce undesirable power swings in the utility system. The ring bus design of the rectenna substation may be helpful in limiting these undesirable oscillations. Sudden Loss of SPS Output

The proposed design of the rectenna power collection system produces power output in blocks of 40,160 , and 320 MW. These blocks of power are so small compared to the total utility system that the sudden loss of even $320 \mathrm{MW}$ will be relatively insignificant.

Any reasonably large utility system today is designed so that loss of any one transmission line produces very little effect. Usually the only consequence is that the load redistributes over other lines and few if any customers are aware of the change. For any sudden change of load or capacity there may also be a small change in frequency, which will be automatically corrected by operation of the generator governors.

It is planned to deliver the rectenna output to an interconnected utility system over several 345 or $500-\mathrm{kV}$ lines. At $500 \mathrm{kV}$ only 4 or 5 lines will be necessary depending on how the power flows into the adjacent systems. At $345 \mathrm{kV}$ probably four double circuit tower lines will be 
required. The adjoining transmission systems may require little if any modification in order to accommodate the outage of either a $500-\mathrm{kV}$ circuit or a $345-\mathrm{kV}$ tower line connecting to the rectenna. The ring bus around the rectenna site should be very helpful in reducing the effect of various outage conditions.

Loss of one quarter of the ring bus would be a loss of 1250 MW which is no more serious than the present day loss of a large nuclear or fossil unit. By the year 2000 such a loss would be even less significant than it is today. The sudden total loss of a 5GW SPS, representing 10 to $15 \%$ of a single utility's capacity, may present an operating problem. Just how serious the problem would be depends on the characteristics of the surrounding utility systems. For. example, in the year 2000 the total peak load of the SERC companies is expected to exceed $260 \mathrm{GW}$. Normal spinning reserve would be close to $3 \%$, in this caseg perhaps $7.5 \mathrm{GW}$. Loss of a $5 \mathrm{GW}$ SPS would use up $2 / 3$ of the spinning reserve, but this would not necessarily be. a serious difficulty. The relationship between an individual SPS and its adjoining system will have to be studied carefully once specific rectenna sites have been selected. Protective and remedial measures would have to be prescribed for each situation.

It appears that the utility system could adapt quite readily to any loss of sps output. There remains, however, the question of what happens to the incident beam energy if 
the SPS loses any of i.ts load? Unused energy from small load interruptions can possibly be scattered and absorbed but what needs to be done about larger interruptions? Is there a limit as to the amount of energy that can be unused at the rectenna? 


\section{Preliminary Operation and Testing}

In a project of this size there will obviously have to be a period of operational testing before the installation can be declared to be in commercial service. Small scale tests involving only a few hundred megawatts of SPS generation should be accepted by the utility system with little difficulty. As the amount of power generation increases however close coordination with the utility will be necessary to insure that they can schedule their facilities to accomodate the t.est. and perhaps make associated tests of their own. One operational proceedure that will require careful examination is the normal start up and shut down of the SPS. As SPS generation is increased utility generation must be decreased unless the start up occurs during the morning period of normal load increase. It appears that SPS output could be changed more rapidly than present conventional base load generation.

For economic and energy conservation reasons the SPS should be operated as close to 1.0 capacity factor as possible (Capacity factor is the ratio of average to rated power output). This may cause some difficulty for the utility system during night time light load periods when it is sometimes necessary to reduce load even on nuclear base load units. At present, daily load following with nuclear units leads to premature failure of fuel elements and the need for expensive decontamination procedures. Large coal fired base 
load units generally have some difficulty in operating at loads much less than 40 or 50 percent of rating. 
System Capacity Mix

When the first SPS goes into service it may represent from 10 to $15 \%$ of the capacity of the surrounding utility system. The normal system reserve margin will probably be 20 to 258 of the peak load. Thus the first SPS could easily represent as much as half of the planned reserve. As a new technology the SPS will no doubt have start-up problems and the utilities may be somewhat hesitant to have half of their reserve in such an uncertain source.

The SPS must be considered base load capacity because the large investment required and the low cost of energy used make it economically desirable to use the unit as much as possible. The utility system can be expected to have a capacity mix that includes about $70 \%$ base load capacity, thus the first SPS will represent from 15 to $20 \%$ of the total base load capacity. This fact must be considered when the utility is deciding on its capacity additions for the year 2000. With a 10 to 12 year lead time the decision to purchase base load capacity may be made as early as 1988 and certainly no later than 1990. The capacity plans of the utility company cannot be easily altered after that date as the plans require a commitment for 4 to 6 units of the 1000 MW size. In the event that the SPS unit is delayed one or possibly two conventional units could possibly be advanced in time to help make up some of the deficiency but probably not all of it. The most likely alternative in this situation 
would be to schedule some additional intermediate or peaking type capacity to replace the SPS, this would alter the capacity mix economics. 
Rectenna Maintenance

Any structure covering over 40 square miles of the earth's surface will be exposed to all kinds of weather and will require continual maintenance.

In most of the southern states lightning will probably be the most frequent and damaging force the rectenna will be exposed to. The southeastern states have isokeraunic levels ranging from 50 to 100 with 60 being a reasonablc avcrage for most of the area. That means, there are 60 days per year, on the average, when thunder can be heard. That number translates roughly into approximately 20 iightning strokes per square mile per year. Assuming the rectenna active dimensions of 6.2 by 8.7 miles, the active area will be about 42 square miles. The average number of lightning strokes to the rectenna would be 840 per year. Further, assuming that any one day of storms could produce as many as 20 strokes to ground, it appears that some part of the rectenna field can expect lightning damage more than 40 days per year. In southern California where the isokeraunic level is only 10 the total number of strokes per year would be only 140 and the number of days might be 10 or less.

The lightning problem poses at least three general types of questions:

(1) What will be the nature and extent of the damage from a iightning stroke? The least that may happen could be a small hole in the ground screen and some dipoles, diodes 
and filters burned up. At worst several panels could be shorted out and severely damaged by welded faults in the 'DC bus. This could happen at each of many different stroke locations.

(2) How do maintenance personnel locate one, or a dozen, faulted panels in 42 square miles of panels? How is one defective diode located out of the 34,000 diodes in one panel? Is it necessary to find each defective diode?

Remembering that the panel rows extend east and west continuously, how do maintenance personnel move a few rows north or south except by going out to the end of a row and returning.

(3) How are repairs made after a fault has been found? For economic reasons it has been proposed that the rectenna elements (dipoles, filters, diodes) be manufactured in a continuous chain fashion. How is one element of the chain replaced? If a panel is severly damaged the whole panel must be replaced, how will this be done?

These three areas of questions raise other questions such as:

(1). Would lightning damage be reduced by grounding every individual support column? What about shield wires or lightning arresters?

(2) To facilitate north-south access within the rectenna field could some panels be hinged in some fashion to form gateways through the rows? 
(3) 'How could fault location be expedited?

(4) What personnel shielding would be necessary to permit maintenance during system operation? The maximum power density of 230 watts per square meter is enough to make a man very warm if absorbed into some kind of protective clothing, especially on a hot day with the sun providing the same amnunt of energy. 


\section{Environmental Considerations}

As presently visualized the rectenna will consist of inclined panels extending in continuous rows in an east-west direstion. Each row will require a north-south ground space of about 100 feet as shown by Figure 10. The two types of rectenna elements presently being considered may have quite different environmental effects.

With a dipole type of rectenna element using an open mesh ground screen much of the incident sunlight could pass through to the ground underneath. The ground vegetation would be subject to some, but not total, shading. The ground screen would allow most of the rainfall through and wind currents would be only partially restricted.

The stripline antenna would be constructed as a solid panel that would be nearly opaque $(80 \%)$ and the ground underneath would be severely shaded. The solid panel construction would deflect rain like a sloping roof and control of erosion at the lower edge would require attention. Wind and ice loadings will be much greater for the solid panel construction.

For either type of rectenna structure there must be sufficient space between adjacent rows for maintenance vehicles to work. This working space as wcll as that underneath the rows of rectenna elements. should produce some ground cover vegetation to control wind and rain erosion. The kind of ground cover required, however, may be different 
than the native vegetation because of the shading produced by the rectenna elements.

Some grading will no doubt be necessary in such a large area. However, it should be kept to a minimum in order to avoid having to make severe changes in the natural drainage pattern. The dipole type rectenna requires less grading because the alignment of the ground plane is much less critical than for the stripline type.

Although some maintenance work on the rectenna will be reyuired at all timcs much of 1 t will arise as the result of storms. Access to all parts of the rectenna after a severe thunderstorm will be very important. The correct ground cover will permit this access without the necessity of constructing a maintenance road down each row of the rectenna array

It will be necessary to remove all trees and shrubs within the rectenna active area. The disposal of this timber refuse may present a difficult and expensive problem. Removal and sale of mature timber might help defrey some of the cost.

certainly not an immediate problem but one that will require atlention in the environmental impact statcment is, how do you retire an SPS installation? The answer probably is that once the land for a site has been assembled it will be too valuable for SPS purposes to be used for anything else. The quantity of material in a rectenna will be so 
valuable that the only possible disposal method will be recycling. In the event that continued use of the land for an SPS site is not possible the same characteristics that made it an attractive SPS site might also make it desirable as an airport. There is also no reason why the land could not be restored to its original usage, however, that would require new roads, utilities, housing, and other associated facilities. 


\section{References}

1. Survey of Satellite Power Systems. C.E. Bloomquist P.R.C. Systems Sciences Company. PRC R-1844 September 1976

2. Impacts and Benefits of a Satellite Power System on the Electric Utility Industry.

Arthur D. Little, Inc. Cont. No. 954639 July 1977

3. Electronic and Mechanical Improvement of the Receiving Terminal of a Free-Space Microwave Power Transmission System. W.C. Brown, Raytheon Company. NASA CR 135194 Contract NAS3-19722 August 197.7

4. Satellite Power System Concept Evaluation Program. Systems Definition Study. Lymdon B. Johnson Gpace Center January 1970

5. Preliminary Baseline SPS Concept Recommendations DOE/NASA, Marshall Space Fliqht. Center January 1978

6. Solar Power Satellite System Definition Study Part II Volume IV - Dl80-22876-4 Microwave Power Transmission System. December 1977 Part III D180-24071-1 Preferred Concept System Definition March 1978 Bneing Aernspare rompany.

7. Satellite Power Systems (SPS) Concept Definition Study SPS Point Design Definition, Final Report Vol. IV Rockwell International SD-78-AP-0023-4 April 1978

8. Small Signal Modulation of the Pacific HVDC Intertie. R.I. Cresap and W.A. Mittelstadt IEEE PAS Trans. Vol. 95 P536-541. 


\section{Problem Areas}

\section{A. utility system}

1. Load and Capacity estimates required to at least the year 2005

2. Transmission plans required to match estimates of Item 1 .

3. Determine the effect of sPS on planned capacity mix

4. Changes in reserve requirements resulting from SPS forced outage and maintenance requirements.

5. What will be the effect of power generation without inertia on frequency control and system dynamic response?

6. Generator control problems arising from eclipse effects.

7. Allowances for seasonal variations in sPS output.

8. Variations in power output due to beam control error.

B. Sociological and Environmental Considerations

1. Time required to obtain land for SPS and new t.ransmission right of way.

2. Relocation of families, schools, churches, graveyards.

3. Remove local utilities, pipelines, railroads and roads.

4. Remove buildings, trees, shrubs and fences and dispose of debris. 
5. Restore ground cover and control drainage.

6. Revise political boundries and provide tax adjustments.

7. Prepare an Environmental Impact statement for each site describing and evaluating the effect of all of these changes.

8. Licensing Requirements

C. Rectenna Maintenance

1. Repair of damage from lighting, wind, rain and other effects.

2. Location, isolation and repair of defective rectenna panels and elements.

3. What is the effect of load rejection on SPS operation?

4. Electromagnetic exposure, shielding, maintenance procedure.

5. What is the electromagnetic and economic effect of declining efficiency?

6. Design to facilitate maintenance.

7. How will north south movement of maintenance vehicles be provided.

8. Provide for control of ground cover and surface drainage.

D. Rectenna Design

1. Power collection and convertor design. 
2. Harmonic filter requirements.

3. AC system characteristics.

4. Voltage regulation and reactive supply.

5. Dynamic Response, open circuit and short circuit characteristics

6. Frequency and magnitude of power variations.

7. System protection and communication shielding requirements:

8. Beam position control characteristics 
METROPOLITAN AREAS SERVED AT 500KV

\section{Metropolitan Areas}

\section{Georgia-Alabama}

Year 2000

Demand-GW

Atlanta

Birmingham

Montgomery

Macon

Columbus

Total

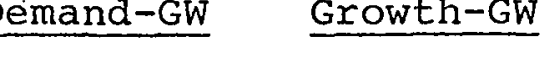

Carolinas

Winston Salem

Charlotte

Greenville

Raleigh

Columbia

Faycttcaville Total

Florida

Miami

W. Palm Beach

Tampa

Lakeland

Orlando

Tittusville

Jacksonville

Total
Two Year
Growth-GW

$\begin{array}{ccc} & & \\ \text { Site } & \text { Site } & \text { Site } \\ \text { Al } & \underline{A 2} & \underline{A 3} \\ 60 & 46 & 131 \\ 142 & 122 & 232 \\ 132 & 163 & 174 \\ 96 & 122 & 53 \\ 80 & \frac{138}{591} & \frac{74}{664}\end{array}$

\begin{tabular}{|c|}
\hline $\begin{array}{r}16.36 \\
13.14 \\
4.15 \\
2.18 \\
2.01 \\
37.84\end{array}$ \\
\hline
\end{tabular}

Distance and Ioad Centers-miles

B1

B2

9.08

7.05

6.54

5.57

4.56

$\frac{2.77}{35.57}$

0.97 .

0.75

0.70

0.59

0.49

$\frac{0.30}{3.80}$

124

54

125

134

72

$\frac{97}{606}$

48

76

173

77

156

$\frac{63}{593}$

ㄷ․ $\quad \underline{C 2}$

12.73

2.55

7.52

1.54

3.24

1.30

$\frac{3.88}{32.76}$

0.86

167

66

0.17

0.50

115

43

0.10

0.22

60

119

0.09

106

152

0.26

$\frac{238}{686}$

137

$\overline{517}$ 
METROPOLITÁN AREAS SERVED AT $500 \mathrm{KV}$

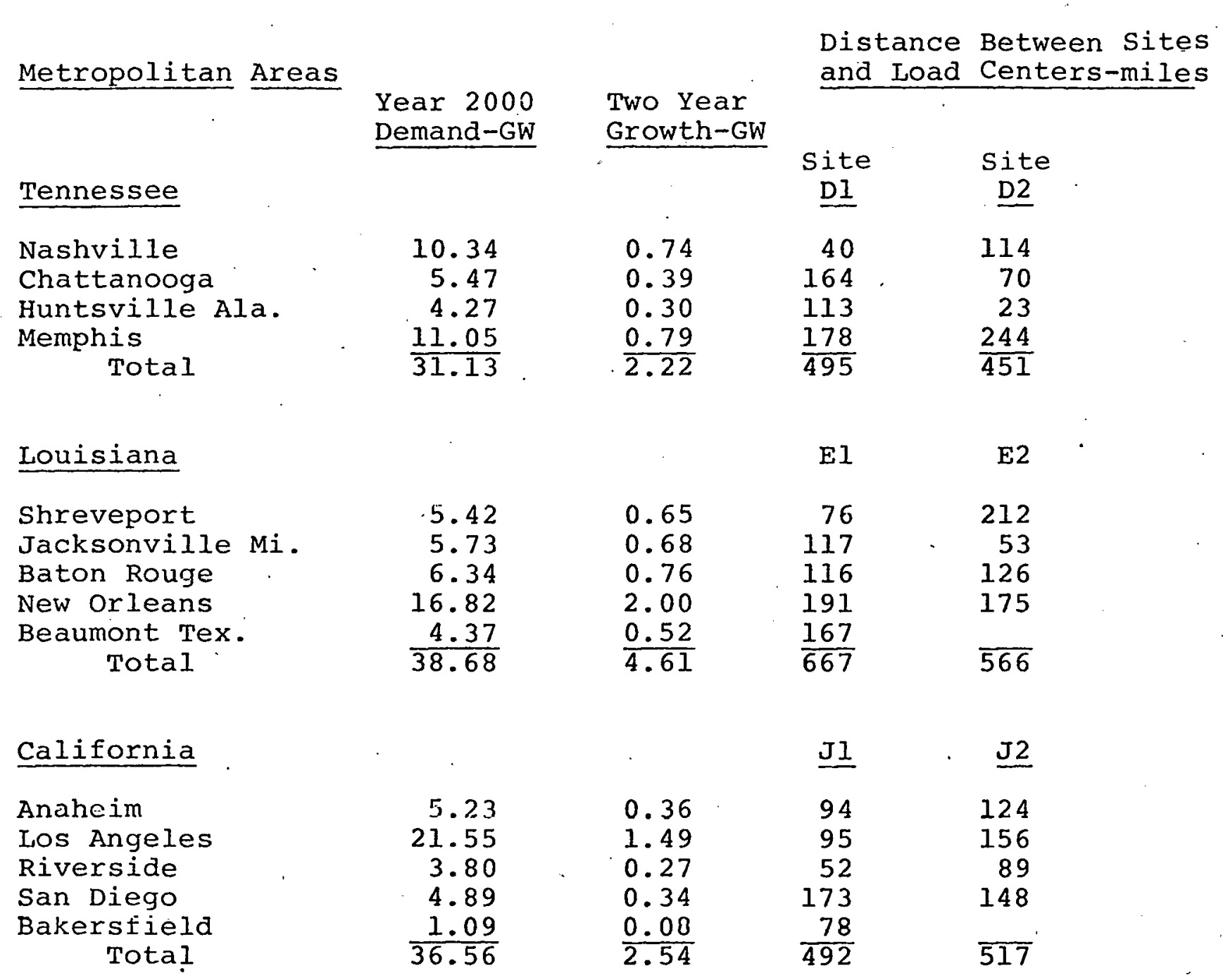


METROPOLITAN AREAS SERVED AT 345KV

\section{Metropolitan Areas}

Year 2000

Demand-GW

Texas-oklahoma

Houslün

San Antonio

Austin

Temple

Total

Dallas-FW

Total

51.56
Two Year

Growth-GW
Distance Between Sites and Load Centers-miles

Site

59

2.38

0.96

0.39

$\frac{2.18}{41.79} \quad \frac{0.2 \mathrm{~L}}{3.94}$

152

130

125

$\underline{G}$

178

65

$\frac{2.46}{4.84}$

2.38

$\underline{\mathrm{H}}$

Dallas-FW

oklahoma City

Tulsa

Total
26.29

8.52

6.69

$\frac{6.69}{41.50}$
2.46

1.01

0.80

$\frac{.80}{4.27}$
Sirrouts Sir.Mi.

$4 \quad 236$

2304

$2 \quad 260$

$\overline{800}$

712

260

$\overline{972}$
62

248

166

332

222

444

$1 \overline{024}$ 


\section{RECTENNA POWER FLOW SCHEMATIC}

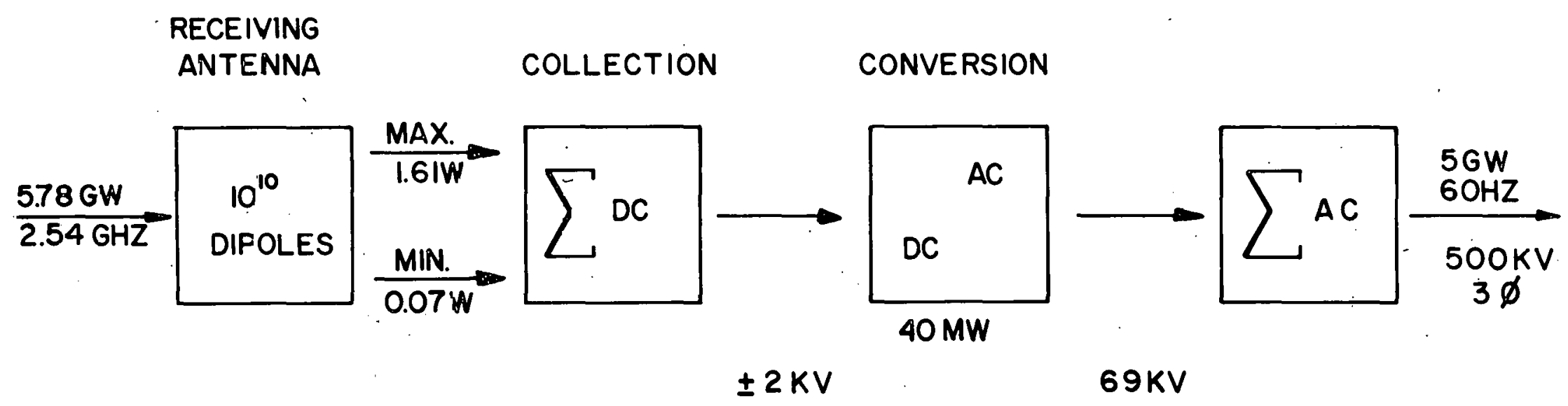




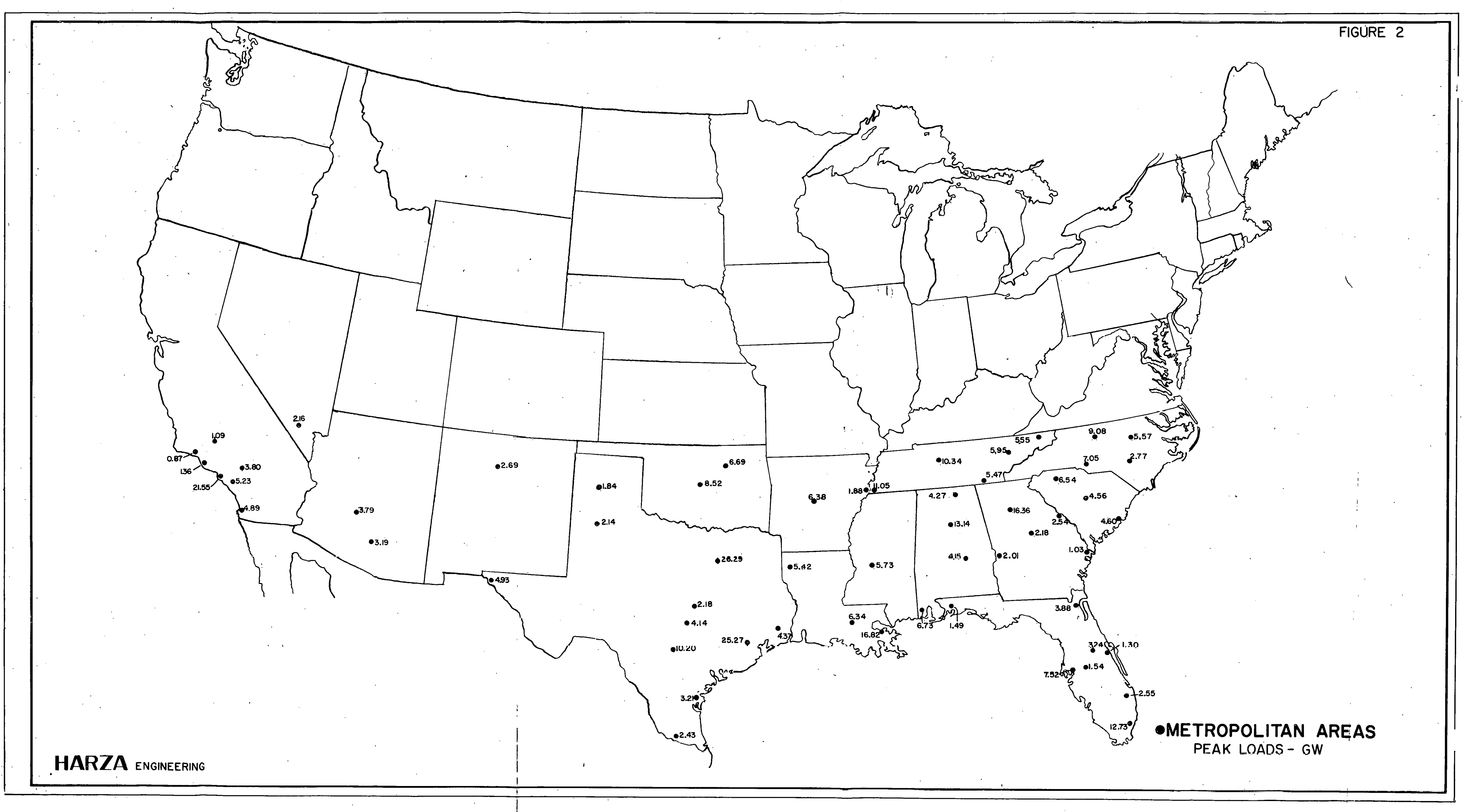




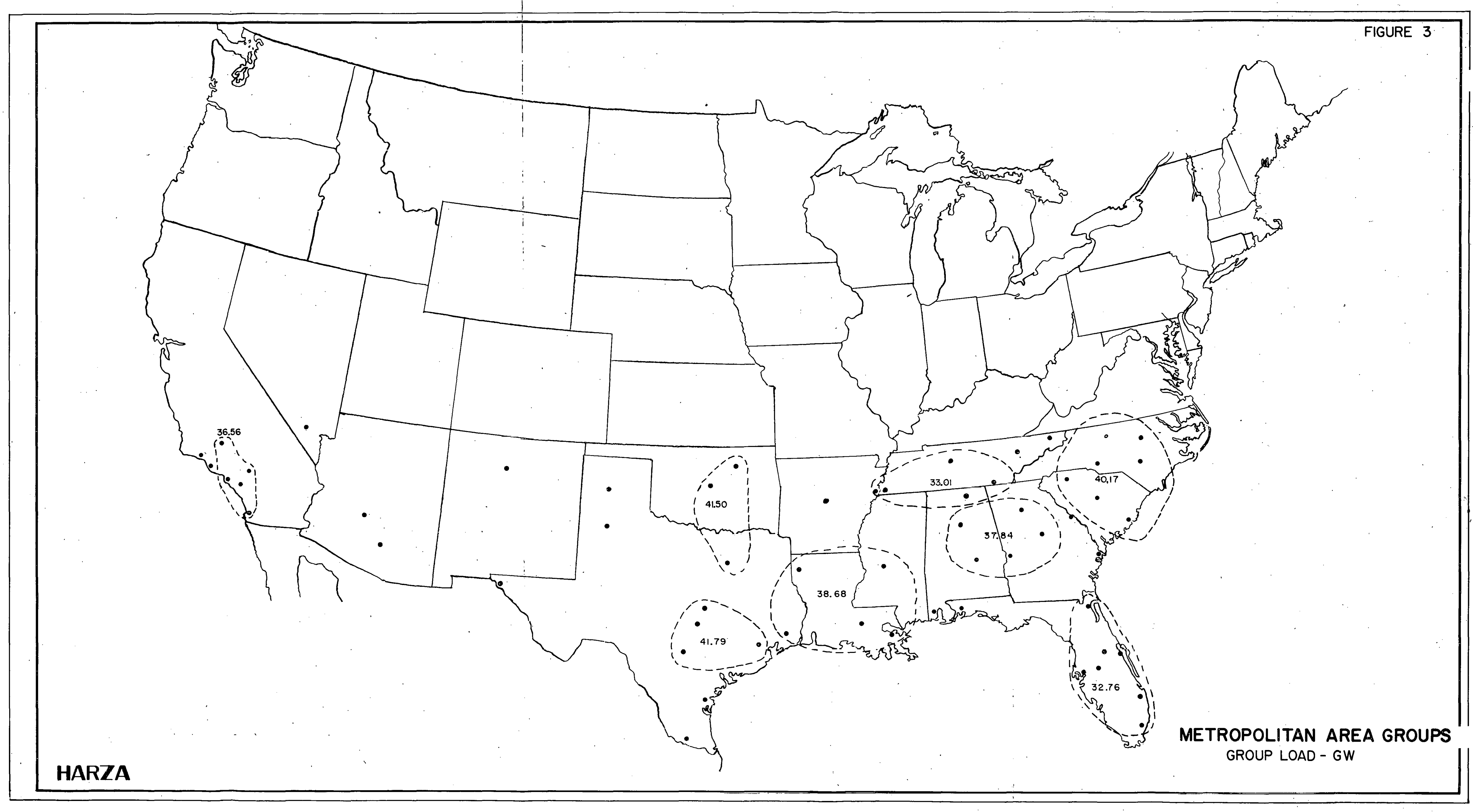




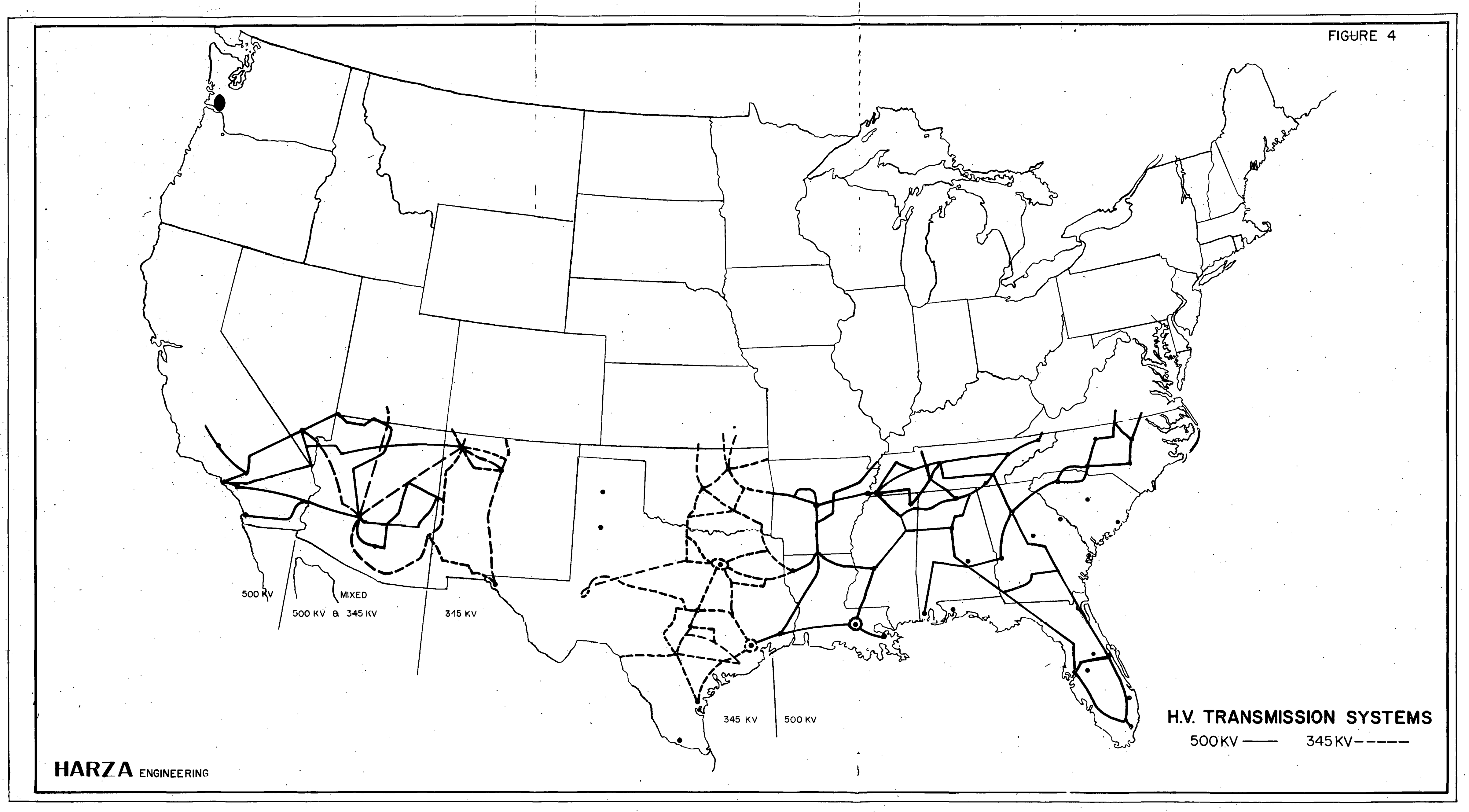




\section{FIGURE 5}

\section{TRANSMISSION LINE LOADABILITY}

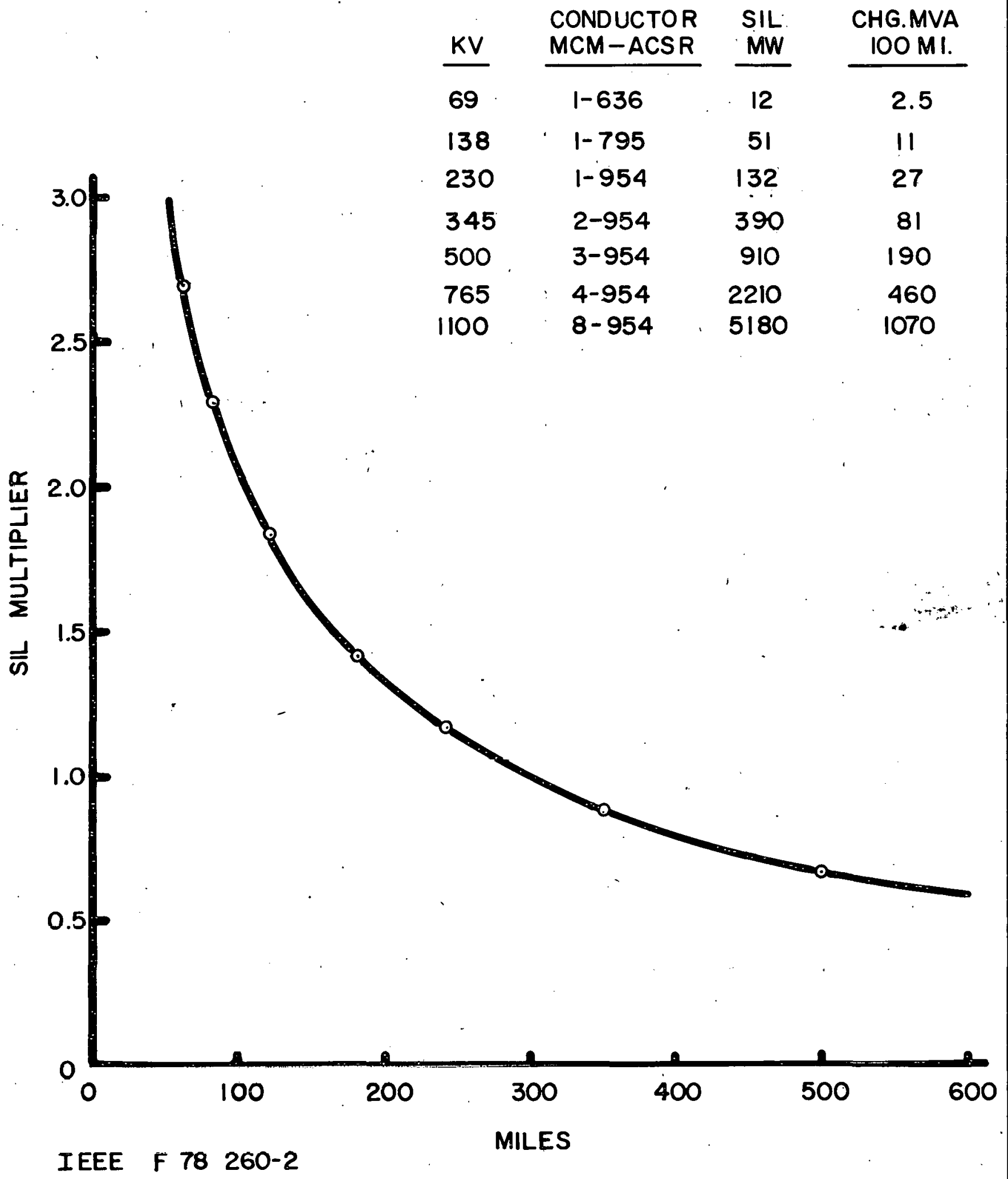

HARZA ENGINEERING CO. 


\section{RECTENNA LAND REQUIREMENT}

ACTIVE AREA

$6.2 \times 8.7=42.4 \mathrm{mi}^{2}$

EXCLUSION AREA

$8.2 \times 11.6=74.7 \mathrm{mi}^{2}$

MAXIMUM PROPERTY

$8.2 \times 11.6=95.1 \mathrm{mi}^{2}$

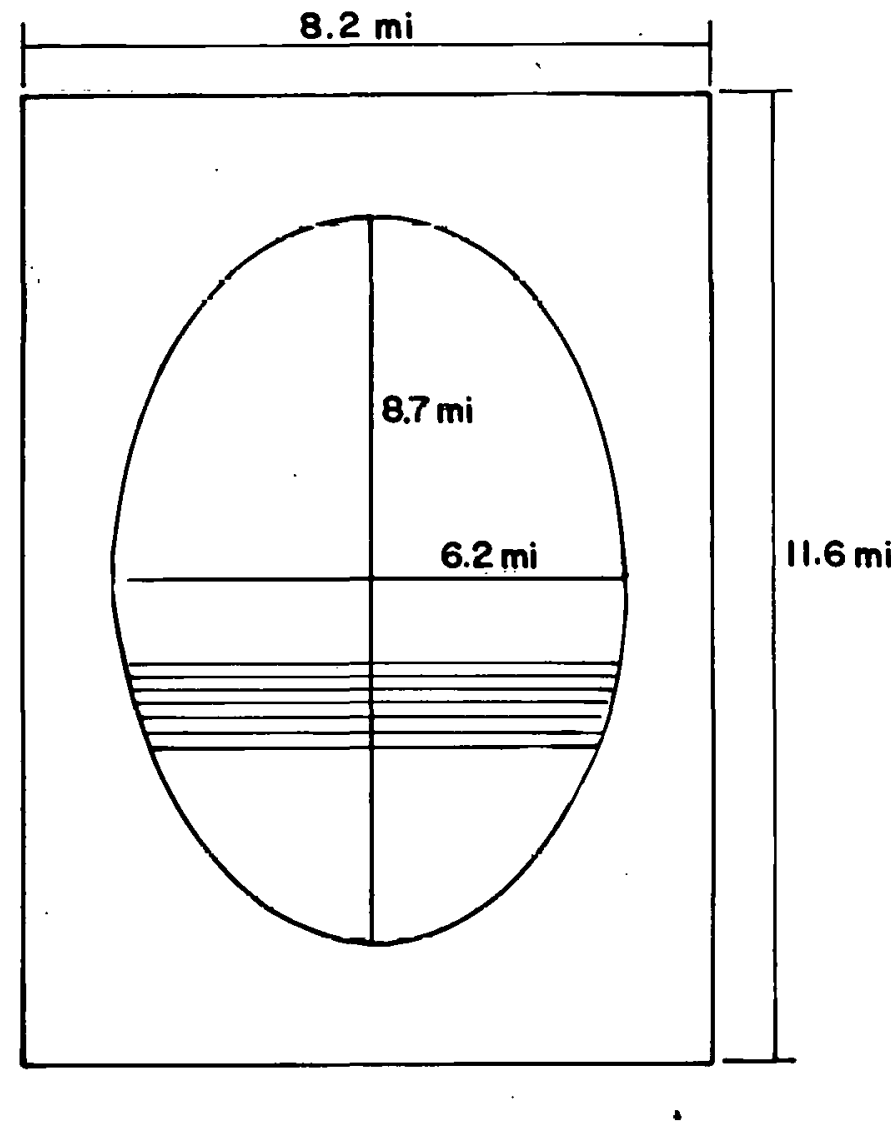

Number of panel rows $\frac{8.7 \times 5280}{101}=455$

Number of panel in longest row $\frac{6.2 \times 5280}{32}=1023$

Panel dimensions $32^{\prime} \times 82^{\prime}=2624 \mathrm{ft}^{2}$

$9.75 \times 25=243.75 \mathrm{~m}^{2}$

Maximum incident power

$230 \mathrm{w} / \mathrm{m}^{2}=56 \mathrm{kw} / \mathrm{panel}$ 


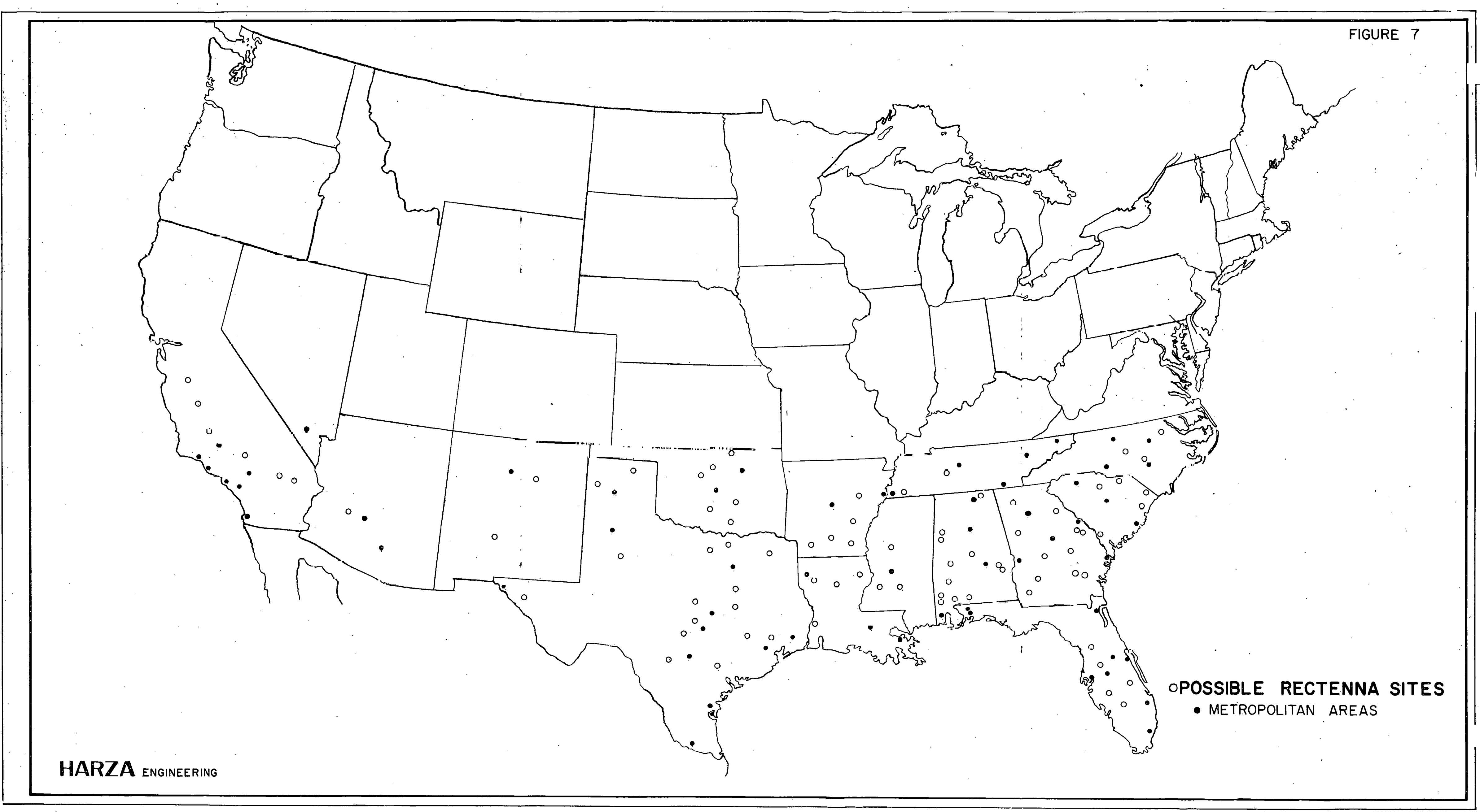




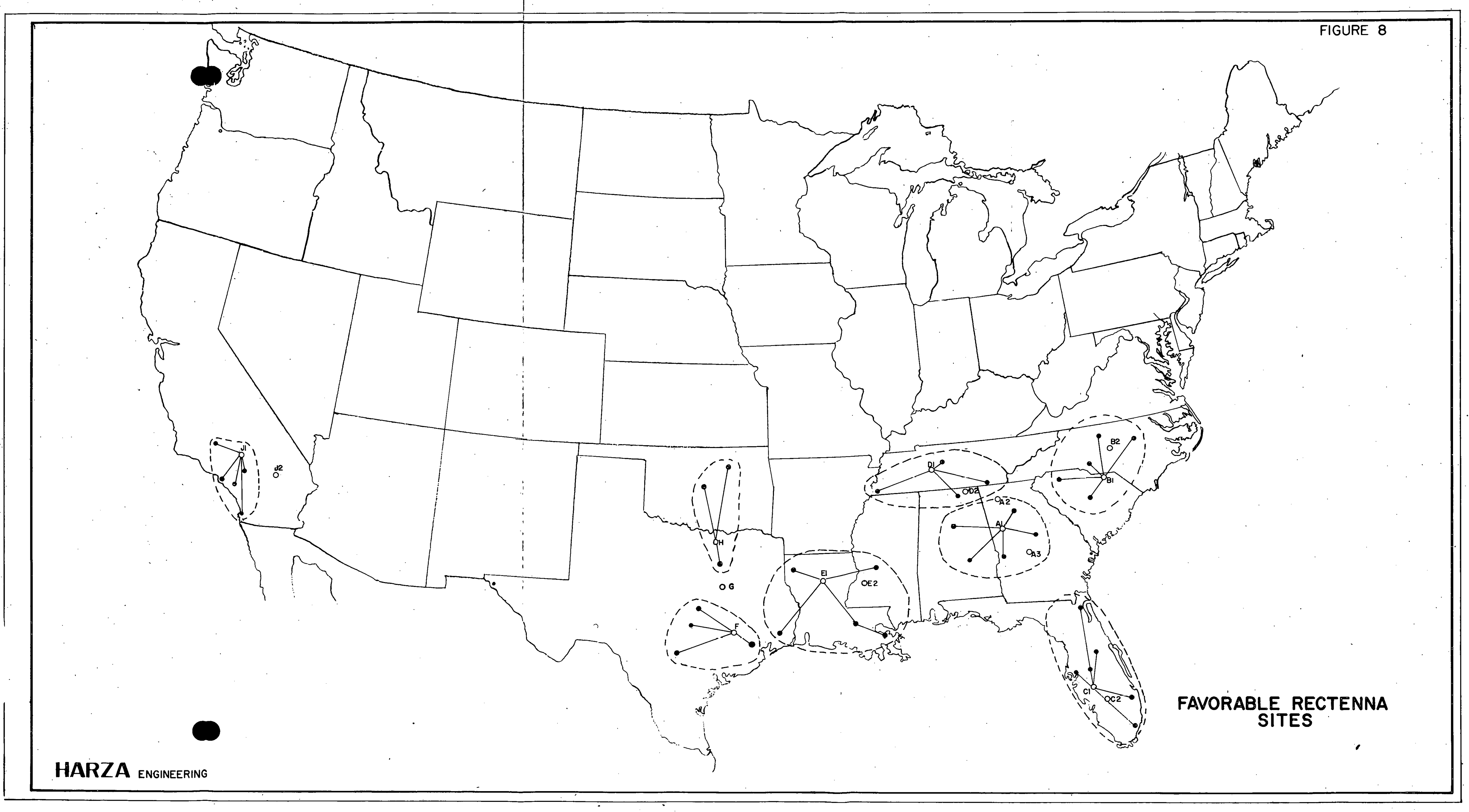




\section{FIGURE 9}
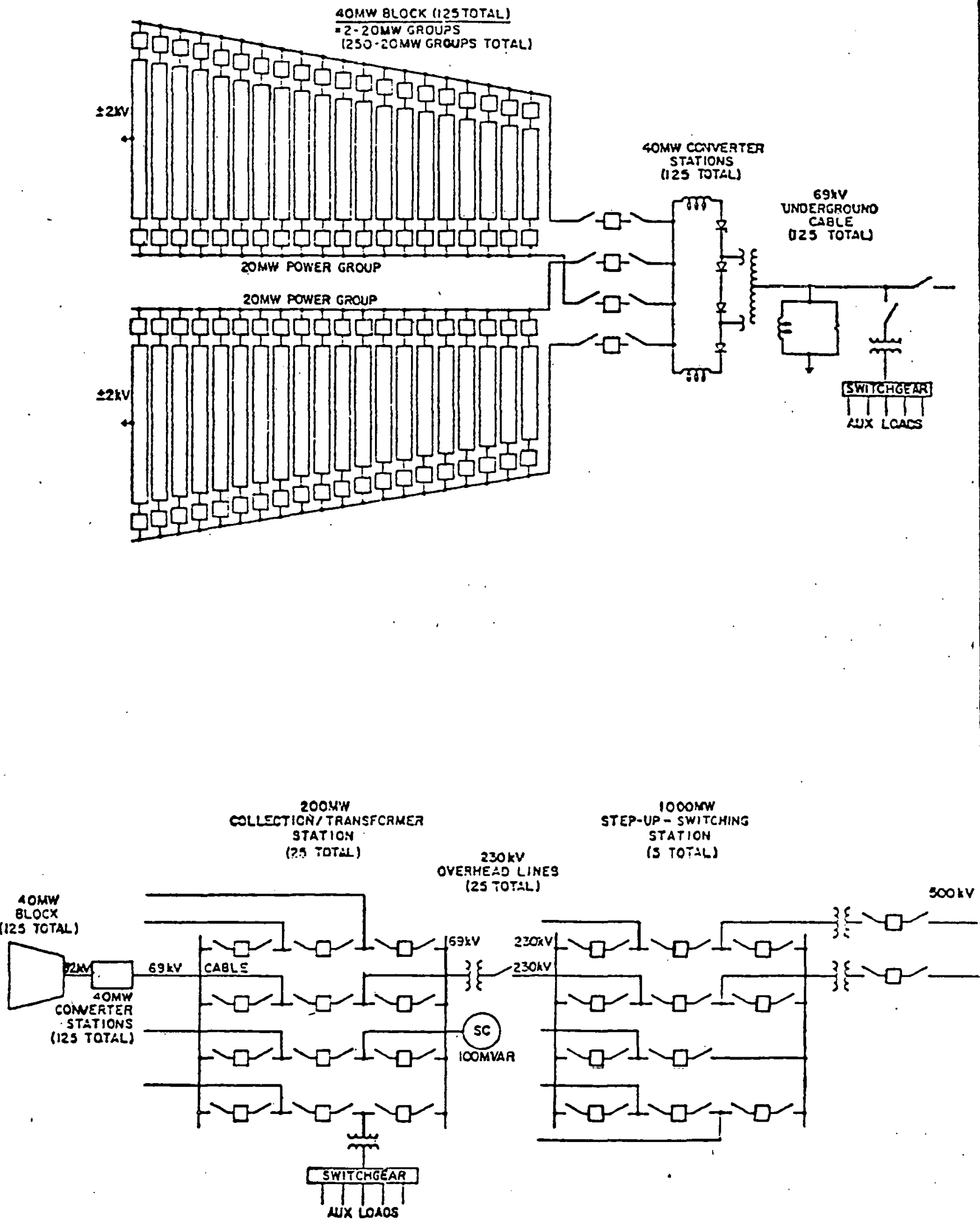

Diagrams from Boeing-GE Report DI80-24071-1 PART III 


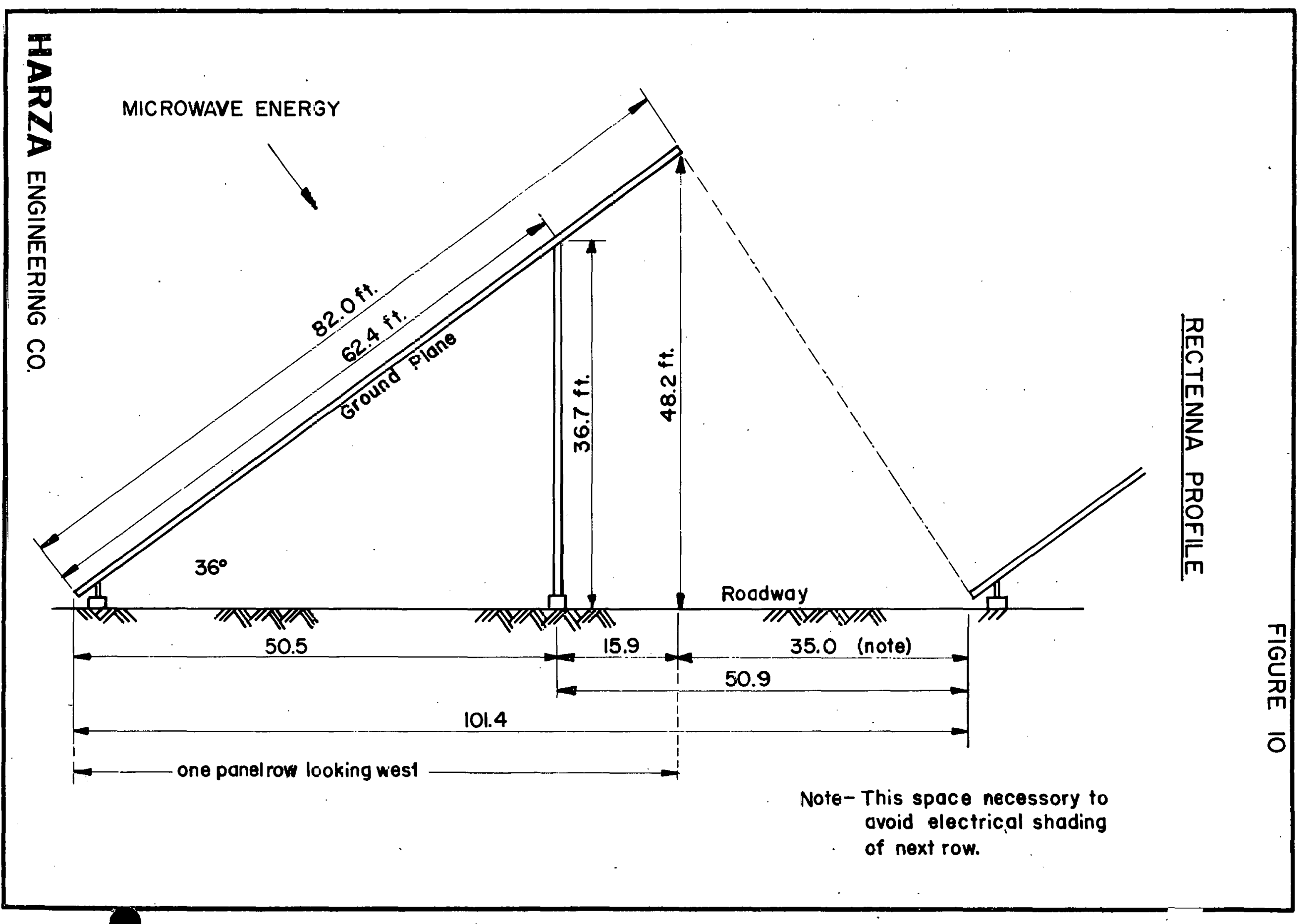


$69 \mathrm{KV}$ COLLECTING SYSTEM

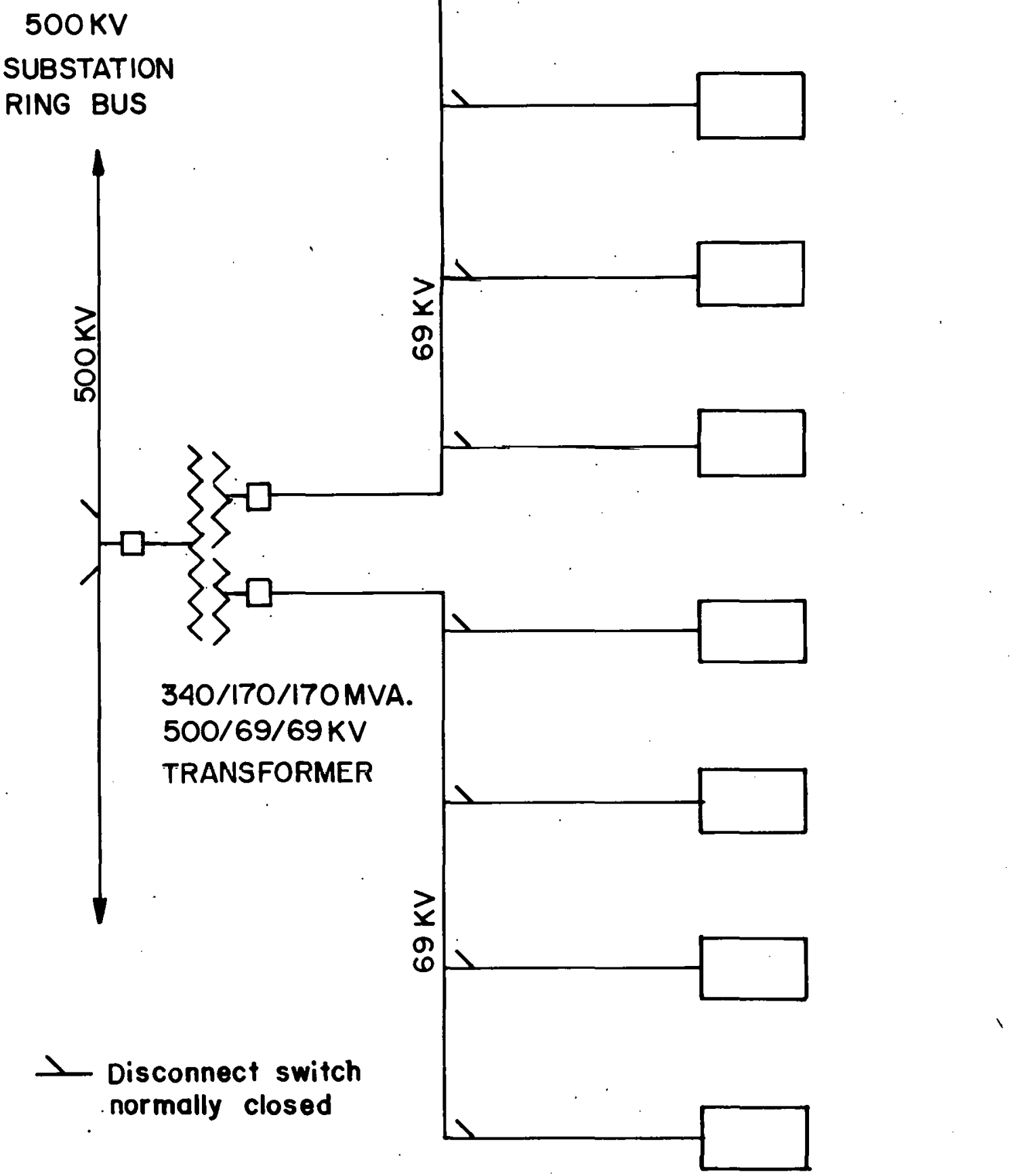

HARZA ENGINEERING CO. 


\section{$500 \mathrm{KV}$ RECTENNA SUBSTATION}

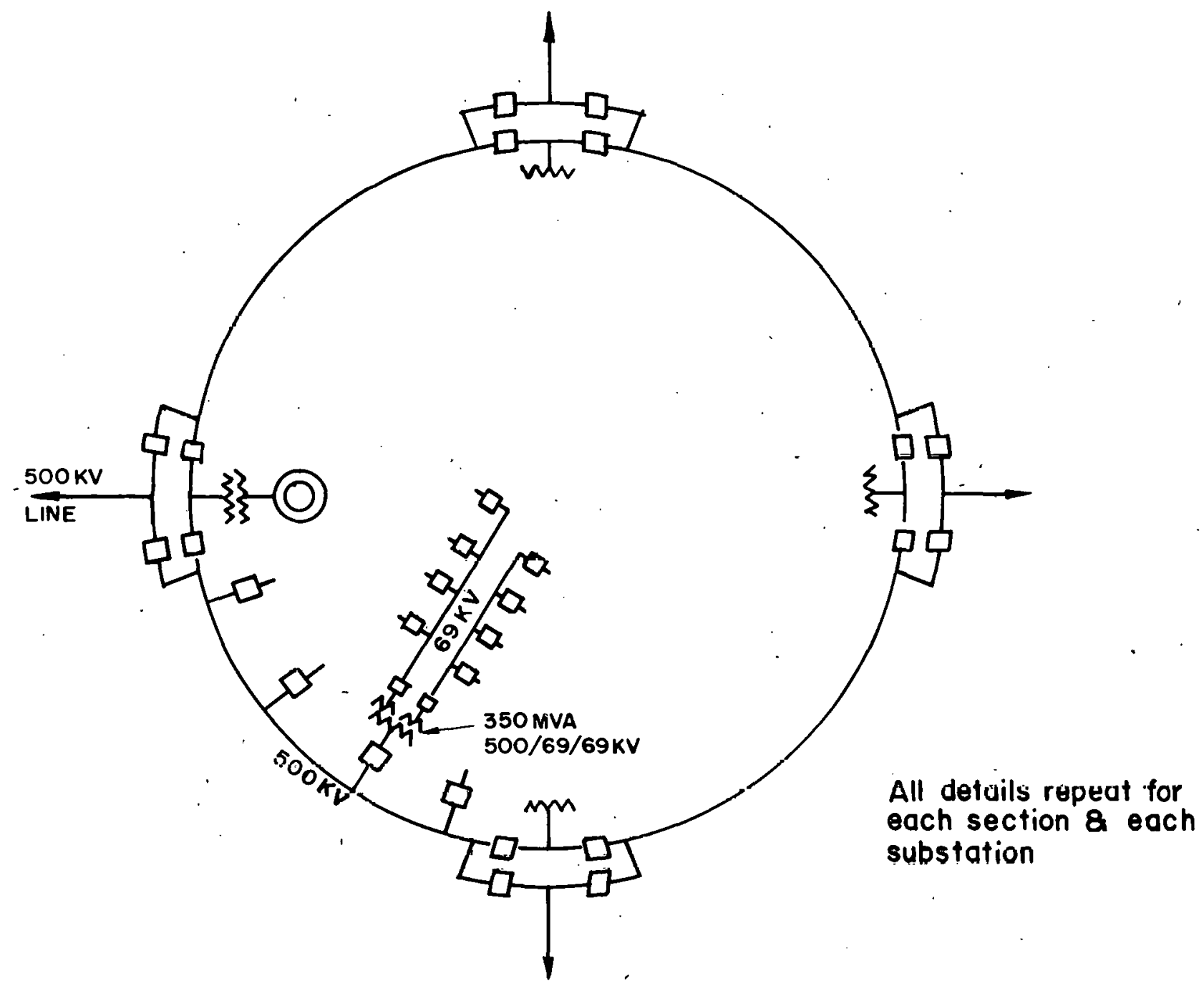

$\frac{5000}{4} \mathrm{MW}=1250 \mathrm{MW}$ per circuit for normal operation

1667 MW per circuit with one line out of service.

$\frac{1250}{40} \frac{M W}{M W}=31.25$ Convertors per circuit

Use 32 Convertors in 8 groups of 4 each

haRZA engineERING co. 


\section{$345 \mathrm{KV}$ RECTENNA SUBSTATION}

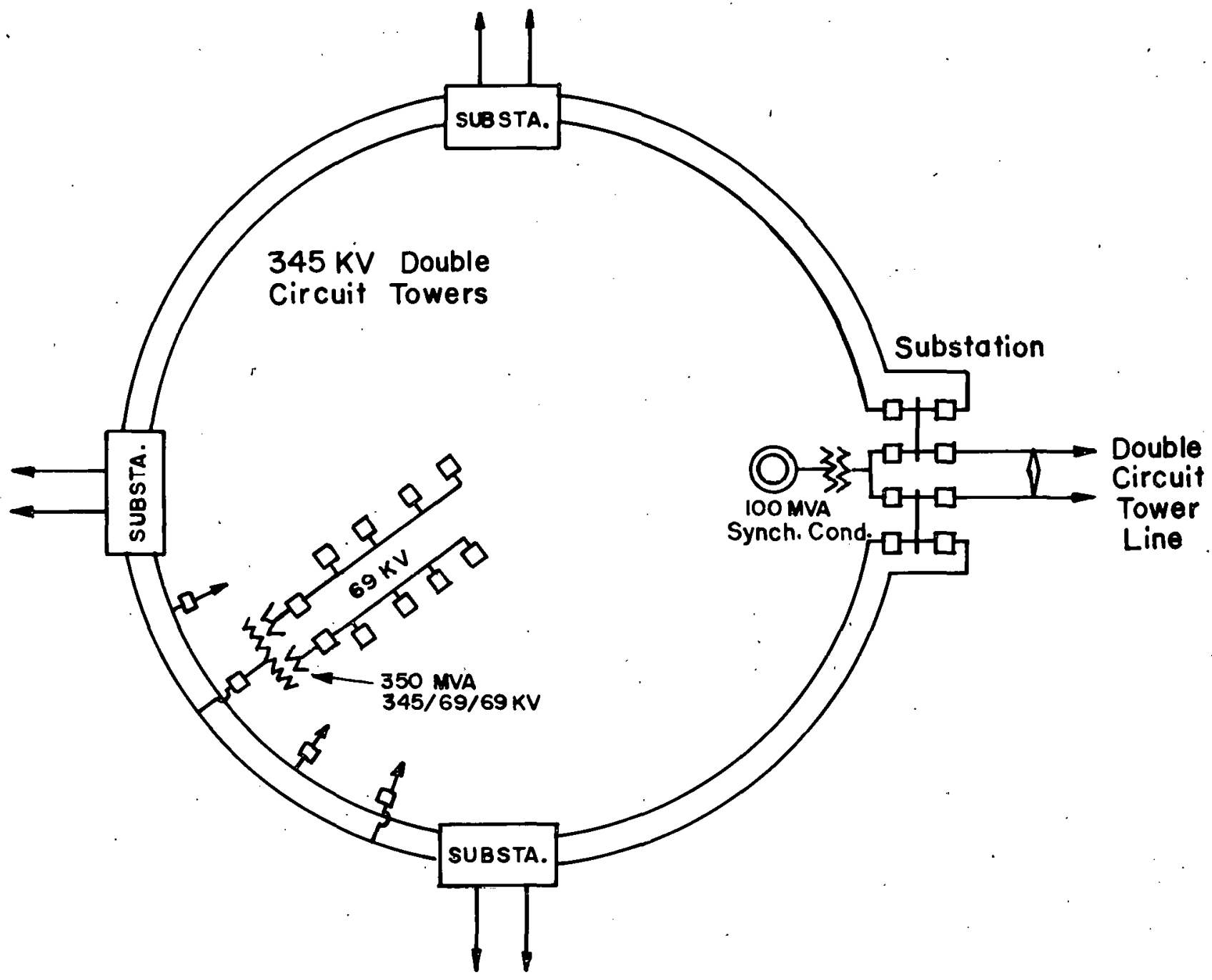

All details repeat for each section 8 each substation

$\frac{5000}{8} \mathrm{MW}=62.5 \mathrm{MW}$ per circuit for normal operation 714 MW with I circuit out of service 833 MW with I tower line out of service 